\title{
REVIEW
}

\section{Effects of climate change on life history: implications for extinction risk in mammals}

\author{
Joanne L. Isaac* \\ Centre for Tropical Biodiversity and Climate Change, School of Marine and Tropical Biology, James Cook University, \\ Townsville, Queensland 4819, Australia
}

\begin{abstract}
Global climate change is predicted to result in the decline and/or extinction of a large number of animal populations worldwide, and the risk of extinction is likely to be greatest for those species already vulnerable - i.e. those with limited climatic range and/or restricted habitat requirements. To date, predictive models have failed to take into account the fact that climate change will alter many of the key life history and ecological parameters which determine a species' inherent risk of extinction, such as body mass, size of geographic range and a suite of reproductive traits. Herein, I review contemporary research on the effects of climate change on extinction risk in mammals, focusing on the capacity of climate change to modify those life history traits that inherently alter species' extinction risk. This review finds strong evidence that climate change has already had marked effects on key life history traits in many mammals. These changes have resulted in both negative and positive effects on reproductive success and adult and offspring survival, with implications for extinction risk in affected species. While the capacity of climate change to alter life history traits in mammals is clear, there is currently little research to clarify how these changes have influenced population growth and dynamics. Other currently overlooked areas of research are also identified.
\end{abstract}

KEY WORDS: Global warming · Environmental variation · Reproductive success · Geographic range Resale or republication not permitted without written consent of the publisher

\section{INTRODUCTION: PREDICTED IMPACTS OF CLIMATE CHANGE ON MAMMALIAN BIODIVERSITY}

Climate change is one of the most significant contemporary threats to biodiversity worldwide and is expected to have a profound effect on both individuals and populations in animal communities (Walther et al. 2002, Thomas et al. 2004, Isaac \& Williams 2007). Indeed, the negative effects of climate change are already apparent in a variety of taxa and ecosystems (Walther et al. 2002). In the geological past, many extinctions are thought to have been associated with 'natural' climatic changes which resulted in habitat loss and ecosystem change (McKinney 1997). However, in the past 8000 yr, extinction rates have risen exponentially and not a single case of extinction can be attributed to a non-human induced cause (Caughley 1994).
While the Earth has experienced much climatic variability over historical time, current climatic changes differ in 2 important ways in terms of their negative impact on biodiversity and extinction rates. (1) The rate of change is generally considered to be unparalleled in the past $10000 \mathrm{yr}$. The latest predictions from the Intergovernmental Panel on Climate Change (IPCC 2007) further indicate that the global mean surface air temperature will continue to increase throughout the 21st century. At the same time, extreme high temperature and rainfall events will also become more common, while snow cover and sea ice will decrease and contribute to rising sea levels (IPCC 2007). (2) Many of the Earth's ecosystems are already stressed by other detrimental human impacts, such as land clearing and habitat fragmentation, making small and isolated populations highly susceptible to the type of stochastic events which climate change will bring, such as wildfires and hurricanes. 
Risk of extinction under predicted climatic changes is likely to differ considerably across geographical and latitudinal gradients and between ecosystems, animal communities and species (Thomas et al. 2004, Isaac \& Williams 2007). For mammals — and indeed most other vertebrate taxa-a variety of studies have demonstrated that species displaying certain ecological and life history traits are more vulnerable to extinction than others (reviewed in McKinney 1997, Purvis et al. 2000). Thus, the life history and ecology of a species will be crucial in deciding its fate under future climatic conditions. In particular, while some generalist speciessuch as those with wide geographic ranges and temperature tolerances - may be better able to adapt to changing conditions, the risk of extinction is likely to increase for many species that are already vulnerable, for example those with limited climatic range and/or restricted habitat requirements.

Herein, I review recent work investigating the effects of climate change on life history traits in mammals, and consider the potential for feedback between climate change and key life history traits to alter, either positively or negatively, the extinction risk of a species under future predicted climatic scenarios.

\section{LIFE HISTORY AND EXTINCTION RISK}

In order to fully evaluate how a particular species is likely to respond to future climatic changes, we must consider how past environmental conditions may have influenced the evolution of their current life history. Indeed, a number of studies suggest that the influence of past environmental conditions on life history strategy will determine how well a species is likely to persist in the face of future environmental changes. For example, general models by Chiba (1998) predict that species with a slow ( $K$-selected) life history inhabiting a previously stable environment will be most at risk of extinction under gradual environmental change. These findings are potentially disastrous for the many rare, endemic mammals which have evolved and persisted through time in environmentally stable refugia, such as montane cloud forests (Graham et al. 2006). However, theoretical models developed by Benton \& Grant (1996) and Tuljapurkar $(1989,1990)$ predict that species with a faster life history will be most affected by rapid changes and extreme events. While these results first appear contradictory, they are more easily explained when the relationship between the prevailing environment and a species' life history is considered. For example, $K$-selected life histories are expected to prevail in stable environments, characterized by high competitive ability, high adult survival and low reproductive output (McArthur \& Wilson
1967). Such species are likely to be initially resistant to perturbations (have high resilience), but will have little capacity to recover from long-term change due to their low reproductive potential and high degree of specialization. Conversely, $r$-selected species inhabiting more variable environments may be more affected in the short term due to their higher population variability. However, species with a faster life history also have a higher capacity for reproduction and through re-colonization events may be less prone to extinction on a more regional scale (Pribil \& Houlahan 2003). Faster generation times may also mean that these species may be better able to adapt to climate changes, either through behavioural or genetic mechanisms, increasing their chance of persistence.

Currently, there is little long-term data to indicate how $r$ - and $K$ - selected mammals will respond to climate change. However, a recent study found that frequent severe weather events may drive selection towards precocial maturation in male pronghorn antelope due to high male mortality (Mitchell \& Maher 2006), suggesting that climatic variation is driving this population towards a faster life history strategy.

\section{IMPACTS OF CLIMATE CHANGE ON LIFE HISTORY AND EXTINCTION RISK}

\section{Contractions and expansions of geographic range}

There is good evidence that historical climatic changes have had a significant effect on the range and distribution of mammals in the past (Guralnick 2007), and recent anthropogenic climate change has similarly resulted in alterations in the geographic and altitudinal range of a variety of taxa. In temperate regions, many species have expanded their range north as average temperatures have increased (e.g. Thomas \& Lennon 1999, Hickling et al. 2006). More recently, there has been evidence of range contractions, particularly in terms of species altitudinal limits, with species that are adapted to cooler conditions retracting their lower altitude margins and becoming more restricted to high altitude habitats (Wilson et al. 2005, Thomas et al. 2006). While the majority of research on range shifts has concentrated on invertebrates and avian species (e.g. Thomas \& Lennon 1999, Wilson et al. 2005), there is some evidence that similar shifts are also occurring in mammal populations; for example, Bowman et al. (2005) speculate that climate warming has resulted in southern flying squirrels Gaucomy sabrinus expanding their range northwards in Canada.

Climate-induced range contractions likely increase a species' risk of extinction: species that are already restricted are likely to be pushed into more restricted ar- 
eas, of less favourable habitat. In turn, this will fragment and isolate populations, make dispersal and recolonization events rare and result in metapopulation dynamics. These isolated populations will be highly susceptible to stochastic events, such as hurricanes and wildfires, which are predicted to become increasingly common in certain regions of the globe as the climate changes (Nicholls \& Alexander 2007). Decreased population connectivity may also have negative consequences for genetic diversity, as recently demonstrated in desert bighorn sheep (Ovis canadensis nelsoni; Epps et al. 2006). For those mammals with an already climatically restricted distribution - such as mountain cloud forest endemics - there will be nowhere left to go (Fig. 1). Thus, if they are unable to adapt to the new climatic conditions, many high altitude species will be lost, even with relatively modest climatic changes. In support of this prediction, McDonald \& Brown (1992) modelled extinctions of montane mammals in the Great Basin (USA) and found that up to $62 \%$ of species may be lost with a $3^{\circ} \mathrm{C}$ increase in temperature. Similarly, Thomas et al. (2004) demonstrate a strong negative relationship between geographical range size and risk of extinction under even moderate warming scenarios. In their analysis, they predict that 15 to $37 \%$ of species in their data set, which includes mammals, will be 'committed to extinction' by 2050, the majority being species with already small geographic range sizes. Learmonth et al. (2006) also predict that marine mammals with restricted geographic distributions and/or water temperature tolerances will be particularly negatively affected.

Feedback between climate change and range expansions - and the consequent effects on the extinction risk of affected species-are, however, less easy to assess. It is likely that generalist species will be favoured by climate change and many introduced and pest species may thus be able to expand their ranges. For example, climatic suitability is an important determinant of the successful establishment and spread of introduced mammals in New Zealand and Australia (Forsyth et al. 2004, Duncan \& Forsyth 2006). Simi- larly, introduced feral mammals are extending their altitudinal range in montane areas of southern Australia as snow cover recedes (Pickering et al. 2004). In other vertebrate taxa, a number of introduced species have already extended their ranges and are predicted to do so further as temperatures continue to change (Munoz \& Real 2006, Nyari et al. 2006; my Fig. 1). Humphries et al. (2004) also predict that many hibernating mammals will also be able to expand their

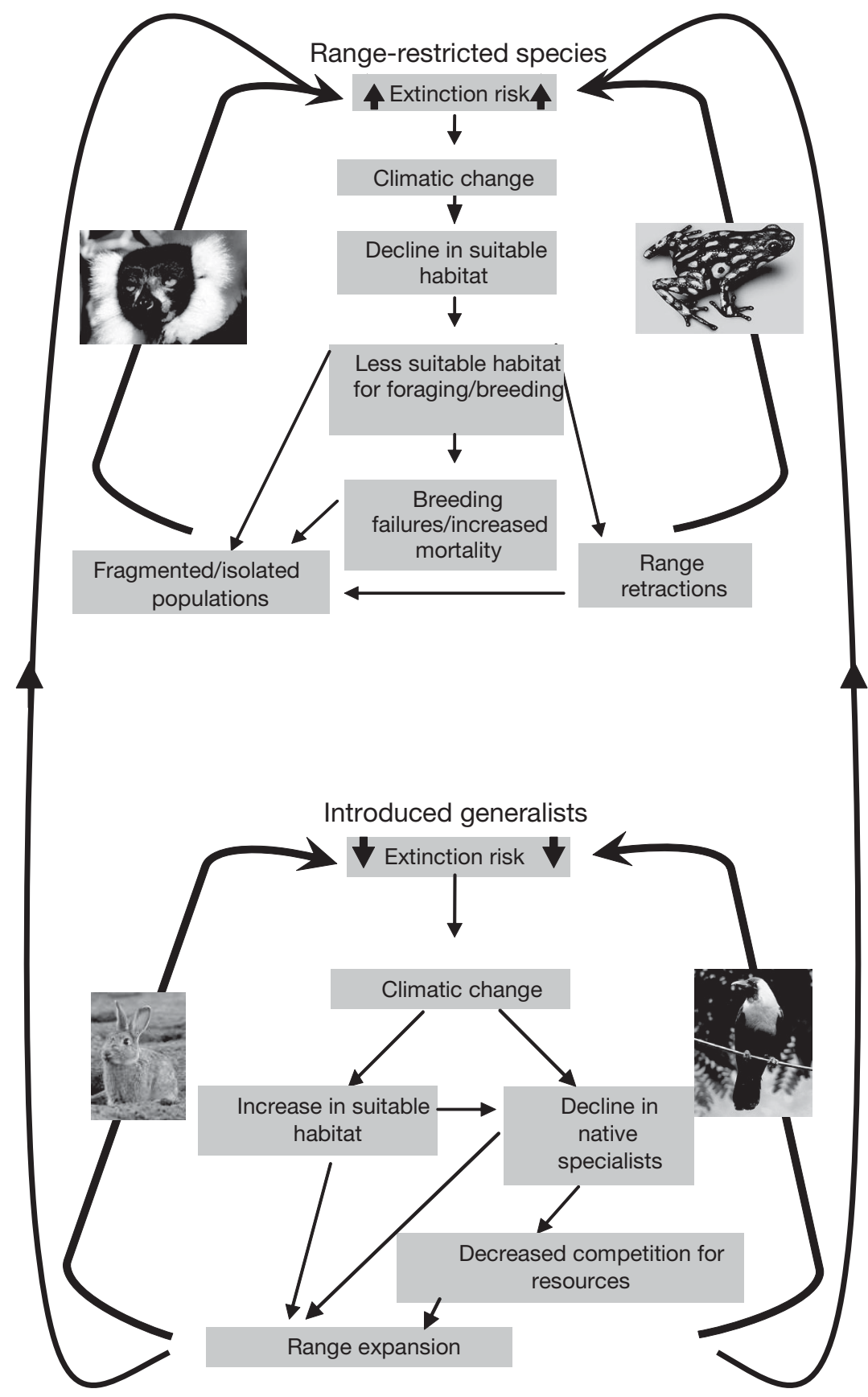

Fig. 1. Flow diagram demonstrating the potential for feedback between life history and extinction risk under climate change for a range-restricted species and an introduced generalist species 
ranges northwards. These range extensions will likely decrease the risk of extinction for the species concerned, at least in the short term. However, the spread of generalists and introduced species may result in the displacement of native and endemic species through intraspecific competition and/or the introduction of exotic diseases and predators (Pickering et al. 2004; my Fig. 1), leading to a less biodiverse, more homogeneous fauna dominated by mobile generalist species (McKinney \& Lockwood 2000). There is evidence from previous mass extinction events to support this theory, with past global climatic and geological disturbances resulting in a low diversity of fauna dominated by a few generalist species (Erwin 1998).

\section{Climatically driven changes in body mass and size}

Numerous studies have demonstrated that body size and mass are predictors of extinction risk in mammals, with larger species usually more vulnerable than smaller species (e.g. Brashares 2003, Cardillo 2003, Cardillo et al. 2005), although in Australia mid-sized terrestrial mammals appear to be most at risk (Johnson \& Isaac in press). The importance of body size in dictating extinction proneness is likely due to the fundamental association between size and other key life history traits, including fecundity, longevity, mating system, trophic level, dispersal ability and energetic requirements (Cardillo et al. 2005). Thus, climate change-body size feedback relationships are likely to have implications for extinction risk.

An increasing body of evidence suggests that climate change has already resulted in significant changes in body mass and size in a number of mammal species. According to Bergmann's (1847) Rule, animals in warmer areas should be smaller than those in cooler areas, as the lower surface area:volume ratio of larger animals may assist in heat conservation in cooler climates. Thus, it could be expected that climatic warming will result in a decrease in body size and/or mass, and a number of studies have demonstrated that this has occurred in some mammals and birds (e.g. Smith et al. 1998, Yom-Tov 2001). However, the converse pattern has also been found in masked shrews Sorex cinereus in Alaska and otters Lutra lutra in Norway (Yom-Tov \& Yom-Tov 2005, Yom-Tov et al. 2006a), and in some other vertebrates (Yom-Tov 2001, Yom-Tov \& Yom-Tov 2005, Chamaille-Jammes et al. 2006).

Studies of 17 endothermic vertebrates (including 4 mammals) in which a clear change in size or mass was demonstrated (Smith et al. 1998, Yom-Tov 2001, YomTov \& Yom-Tov 2004, 2005, Fernandez-Salvador et al. 2005, Yom-Tov et al. 2006a,b) showed that $71 \%$ $(n=12)$ of the vertebrates investigated declined in body mass. For those studies where latitude was reported, the latitude of species which declined in mass ranged from 31 to $52^{\circ} \mathrm{N}$, while the latitudinal range of species which showed an increase in mass was 37 to $65^{\circ} \mathrm{N}$. Thus, while the prevailing pattern of a decline in body mass conforms to the predictions of Bergmann's Rule, it is notable that some species, particularly those at higher latitudes, show the reverse pattern. At more northerly latitudes and/or at high altitudes, global warming may have decreased winter severity and resulted in an increase in food availability, allowing species a longer growth period and the attainment of higher body mass. Further data on a variety of species across different latitudes will be required to assess the pervasiveness of this pattern.

Predicting the effects of a climatically induced decline in body size on other life history traits - and, as a result, on extinction risk-is complex. On the one hand, there is evidence to suggest that in organisms which show intraspecific variation in size across their geographic range, populations with smaller body size show earlier maturation, higher reproductive rates but a shorter lifespan: essentially a faster life history compared to populations with larger body size (Lardies \& Bozinovic 2006). Thus, given predictions of extinction risk based on life history and body size, we might expect that a shift to a smaller body size should result in a decrease in extinction risk. However, in some regions climate change is also likely to be associated with greater variability in resource availability (e.g. Song et al. 2006), breeding season length (see 'Reproductive parameters' below) and an increase in stochastic weather events (IPCC 2007, Nicholls \& Alexander 2007). Thus, while metabolic changes associated with a decline in size mean that longevity may be reduced, predicted increases in reproductive success may not be achievable for some species, resulting in an increase in extinction risk.

In general, large body size is predicted to increase extinction risk in mammals due to a combination of factors, including slower reproductive rates, greater range requirements and a higher trophic level (Purvis et al. 2000; Cardillo et al. 2005). Thus, we might predict that an increase in body mass due to climate change will be detrimental to the resilience of a species. However, intraspecific studies have demonstrated that individuals or populations with greater body size generally have greater reproductive success and/or survival (Yoccoz \& Mesnager 1998, Du et al. 2005). In support of this prediction, an increase in body size related to climatic warming has resulted in an increase in reproductive success in a mountain population of the common lizard Lacerta vivipara, leading the authors to conclude that this population has benefitted from cli- 
mate change (Chamaille-Jammes et al. 2006). However, the short-term benefits of an increase in body size may be negated by the longer term consequences of other factors associated with increased body size, including slower growth, later maturation, increased resource requirements and an increased home range size, all of which may negatively affect population size and persistence.

A further consideration is that changes in body size, due to factors such as climate change and associated environmental variation, may affect one sex more than the other. For example, resource scarcity can constrain the growth of males and females differentially in mammals and this can influence the degree of sexual dimorphism, and feed back into mating strategy and system (reviewed in Isaac 2005). The implications of changes to mating systems and, as a consequence, sexual selection, are discussed in detail in 'Reproductive parameters' below. In mammals, it has also been demonstrated that climatic conditions at birth can influence life history traits, such as body mass and, as a result, lifetime reproductive success, in individuals throughout their lives, giving rise to a 'cohort effect' (Albon et al. 1987, Forchhammer et al. 2001). Thus, if successive cohorts are negatively affected by adverse climatic conditions over a sufficient period of time, consecutive reproductive failures and/or decreased offspring survival could decrease population size and slow recovery rates, increasing the risk of extinction. To add to the already complex nature of the relationship between climate and body mass variation, a recent study of Norwegian moose Alces alces demonstrates that the magnitude of environmental effects on body mass is influenced by both the initial body size and density of the population in question (Herfindal et al. 2006).

\section{Reproductive parameters}

While the studies reviewed above demonstrate that climatically induced variation in body mass and size can indirectly affect reproductive success, climate change can also have a direct influence on a variety of reproductive parameters.

Breeding seasonality, and in particular length of breeding season, are key determinants of reproductive success and output for most species. Climatic changes undoubtedly have the potential to alter the degree of breeding seasonality for a species, but the direction and magnitude of the effects of climate change on breeding seasonality will likely depend both on the nature of the climatic change and current climatic conditions. On the one hand, an increase in unfavourable conditions, such as wetter periods towards the start or end of the breeding season, may result in a shortened breeding season and a decline in reproductive output. On the other hand, warmer weather may increase the length of the breeding season, particularly in northerly latitudes. For example, Reale et al. (2003) demonstrate an advance in the timing of breeding in red squirrel Tamiasciurus hudsonicus in Canada of $18 \mathrm{~d}$ in the course of $10 \mathrm{yr}$, related to warmer spring temperatures, while Langvatn et al. (2004) show that reproduction in red deer Cervus elaphus is constrained by short summers in northerly latitudes.

Reproductive success in mammals is also often related to climatic conditions, such as temperature and rainfall, during both the gestation and lactation periods. However, these relationships can be either negative or positive depending upon the species and geographic region involved (e.g. Kruuk et al. 1999, Russell et al. 2002, King et al. 2005). A recent study on seabirds demonstrates the potential complexity of the relationship between temperature and reproductive parameters; the effect of the North Atlantic Oscillation (NAO) on breeding success in the birds changed from positive in the south to negative in the north (Sandvic et al. 2008). Thus, while some studies suggest that positive effects are most likely to be seen in colder regions where summers will probably become longer and winters less severe, the final outcome is likely to be compounded by a variety of factors.

Research has further demonstrated that variation in breeding seasonality among populations of species which occupy large geographical ranges can also influence the degree of sexual selection, secondary sexual characteristics and the degree of polygyny (Quin et al. 1996, Storz et al. 2001, Isaac \& Johnson 2003). Thus, climate-induced variations in seasonality will likely affect mating systems and sexual selection, the consequences of which are discussed below. It is likely that the direction of change will depend upon the mating system of the species in question and patterns of temporal and spatial dispersion of receptive females.

While variation in breeding seasonality and length can exert an indirect effect on mating system and sexual selection in animal populations, there is also good evidence-largely from avian studies, e.g. Møller \& Szep (2005), Weatherhead (2005a,b) - that climate variation can directly influence sexually selected characters, mating systems and patterns of paternity. More recently, Twiss et al. (2007) have also demonstrated that climatic variation can influence the opportunity for sexual selection in an aquatic mammal, the grey seal Halichoerus grypus. These authors found that in wetter years, polygyny potential is greater and only the most competitive males are successful, while in drier years a greater proportion of previously unsuccessful males are able to sire offspring. 
The consequences of a change in the magnitude and direction of sexual selection are difficult to predict. Negative effects of increased sexual selection and polygyny potential may include an increase in extinction risk through the reduction of effective population size by excluding non-competitive males from mating (Prinzing et al. 2002). Sexual selection may also work antagonistically with natural selection to make the sexually selected (often larger) gender more prone to predation, parasites and/or resource shortages (see review in Isaac 2005). On the other hand, sexual selection may reinforce natural selection if sexual traits also signal individual fitness and can facilitate communication between the sexes, harmonizing reproductive efforts (Prinzing et al. 2002). It may also promote local adaptation by reducing gene flow (Prinzing et al. 2002). Additionally, a decline in polygyny potential and sexual selection may also have negative consequences for the genetic fitness of a population if less fit individuals are able to sire more offspring (e.g. Coltman et al. 2003).

Finally, climate change may also directly influence reproductive success through the mistiming of reproduction with peak food availability or through negative effects on prey populations. Research so far indicates that trophic mis-match will likely be a larger problem for species at higher trophic levels, such as insectivores and carnivores. For example, there is good evidence that the mistiming of avian reproduction with caterpillar biomass has resulted in failed reproductive attempts and population declines in numerous bird species (reviewed by Visser \& Both 2005). At present there appear to be no comparable studies on mammals, but it is likely that insectivorous mammals will be similarly negatively affected as they rely on emerging insects in spring for survival. Such effects also appear to be a common phenomenon in oceanic carnivorous mammals. First year survival of elephant seal Mirounga leonina pups is greatest during El Niño Southern Oscillation (ENSO) events when the water is cooler and more productive - and thus since climate change is expected to increase ocean temperatures, it is likely to have a negative effect on pup survival (McMahon \& Burton 2005). Similarly, pup production in South Georgian Antarctic fur seal Arctocephalus gazella has declined considerably since 1985 with increasing sea surface temperatures, likely associated with low availability of food (krill) (Forcada et al. 2005). Climatic changes have also been linked to an increased risk of star- vation in harbour porpoises Phocoena phocoena in Scotland, due to negative effects on the distribution and abundance of their primary prey-sandeels (MacLeod et al. 2007).

In summary then, there is mounting evidence that climate change is affecting a variety of interacting factors which relate directly to a species' reproductive success (Fig. 2), and thus its ability to recover from stochastic events and persist into the future. Untangling these complex relationships in order to predict outcomes will be extremely difficult in the face of opposing factors that in some cases increase reproductive output (e.g. a longer breeding season) and in other cases decrease it (e.g. a decline in body size). The relative effect of each factor on reproductive success - and the antagonistic or synergistic effects of 2 or more factors - will determine the final outcome.

\section{CONCLUSIONS AND FUTURE RESEARCH}

The studies reviewed here demonstrate that climate change has resulted in changes to key life history and demographic traits such as body size, breeding seasonality and geographic distribution in a variety of mammals worldwide. However, this review also highlights the apparently contradictory nature of many studies and predictions. Much of this confusion results from our current lack of knowledge regarding the complex interactions between factors such as latitudinal range, climatic seasonality and breeding systems (see also Millien et al. 2006), and, indeed, a still incomplete

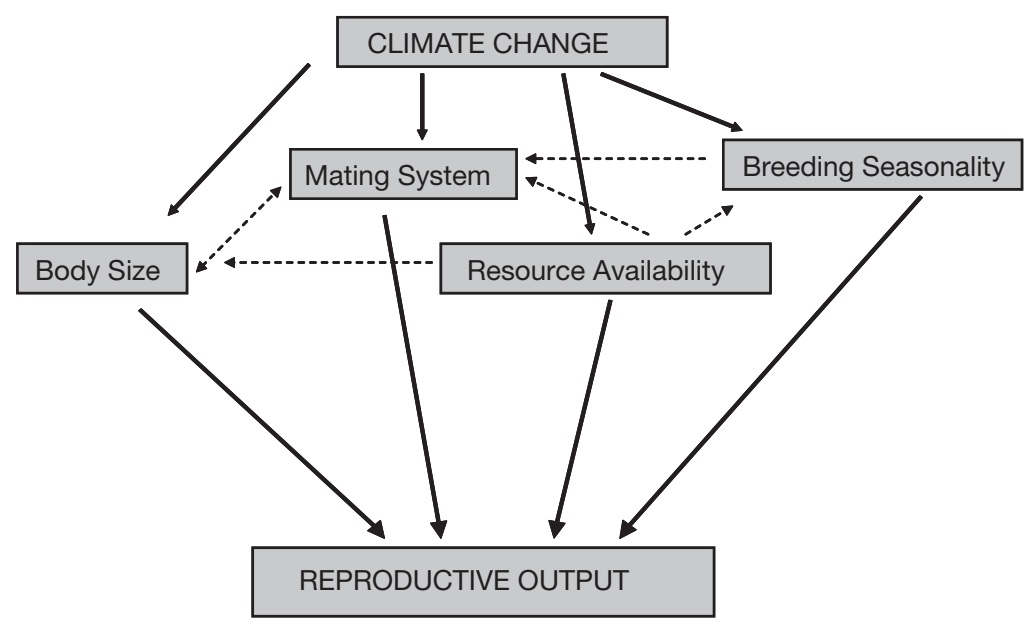

Fig. 2. Path diagram highlighting some of the complex interactions which are likely to occur between reproductive parameters and reproductive output under predicted climate changes. Solid lines: direct relationships between climate change, reproductive parameters and ultimate reproductive output; dashed lines: interactions between reproductive determinants 
understanding of how key life history traits co-vary with each other. However, while this research field is clearly still in its infancy, there do appear to be some patterns emerging. In particular, studies indicate that for a number of generalist species, the demographic changes brought about by climate change may be beneficial, resulting in range expansions and a longer and more productive breeding season, thus reducing the risk of extinction in these species. However, the outlook is less optimistic for specialist and endemic species, which may suffer a reduction in suitable geographic range, experience negative effects on reproductive performance and suffer interspecific competition or increased predation from generalist species. Studies to date also suggest that the majority of mammals are likely to respond to climate change with a decrease in body size.

Research into the effects of climate change on life history traits and biodiversity in general is accelerating at a rapid pace. However, at present there is little research to identify how changes to life history and ecological traits will affect the demographics and future persistence of affected populations. For example, a key challenge will be to understand the implications of shifts in body mass on population dynamics and persistence. One potentially useful approach to predicting species-specific responses to climate change is the use of historical and/or fossil records. Smith \& Betancourt (2006) recently integrated studies of museum specimens and records from paleomiddens for woodrats (Neotoma spp.) to identify past temperature thresholds which led to local extinctions and range alterations. The authors then utilized this information to predict the potential response of woodrats to contemporary climate change. This methodology could be successfully applied to many other species for which there are museum specimens to predict responses.

The potential of a species to adapt to climatic changes, either through behavioural or genetic means, also remains an area where further research is essential, as such adaptations may ameliorate negative effects in some species and reduce the apparent risk of extinction. A further, currently overlooked avenue of research is that of antagonistic or synergistic effects between climate change and other anthropogenic threats such as habitat fragmentation due to hunting, and introduced species. Studies have demonstrated that such anthropogenic threats can have undesirable consequences for life history traits in mammal populations (Jachmann et al. 1995, Coltman et al. 2003), and climate change may exacerbate these and increase the risk of extinction in some species. There is also a general paucity of research on the responses of species in the tropics and southern hemisphere, which should be addressed; the studies reviewed here indicate that both the nature of climate change, and its subsequent effects on life history and ecology, will differ significantly for southern hemisphere mammals.

Finally, while long term climatic changes will clearly affect life history and extinction risk, in the short term it will be extreme temperatures or weather events which will likely have the most impact on animal populations. The life history of a species will largely determine whether a species is vulnerable to such an event and, if it is, whether it can survive and recover. For example, a recent study demonstrates that mortality among Australian flying-foxes during an extreme temperature event varied both between species and between the sexes (Welbergen et al. 2008). More understanding of species-specific differences in extreme temperature tolerances, and the probability that a species will be exposed to temperature extremes, is thus critical in order for us to be able to implement conservation plans to minimize exposure to vulnerable species.

Acknowledgements. I thank S. Williams, Y. Williams and C. Johnson for valuable discussions, and B. Goodman and L. Valentine for useful comments on earlier versions of the manuscript. Research for this study was funded by James Cook University RAP and MTSERF grants to S. Williams.

\section{LITERATURE CITED}

Albon SD, Cluttonbrock TH, Guinness FE (1987) Early development and population-dynamics in red deer. II. Densityindependent effects and cohort variation. J Anim Ecol 56:69-81

Benton TG, Grant A (1996) How to keep fit in the real world: elasticity analyses and selection pressures on life histories in a variable environment. Am Nat 147:115-139

Bergmann C (1847) Uber die Verhaltnisse der Warmeokonomie der Thiere zu ihrer Grosse. Göttinger Studien 1: 595-708

Bowman J, Holloway GL, Malcolm JR, Middel KR, Wilson PJ (2005) Northern range boundary dynamics of southern flying squirrels: evidence of an energetic bottleneck. Can J Zool 83:1486-1494

Brashares JS (2003) Ecological, behavioral, and life-history correlates of mammal extinctions in West Africa. Conserv Biol 17:733-743

Cardillo M (2003) Biological determinants of extinction risk: Why are smaller species less vulnerable? Anim Conserv 6:63-69

Cardillo M, Mace GM, Jones KE, Bielby J and others (2005) Multiple causes of high extinction risk in large mammal species. Science 309:1239-1241

Caughley G (1994) Directions in conservation biology. J Anim Ecol 63:215-244

Chamaille-Jammes S, Massot M, Aragon P, Clobert J (2006) Global warming and positive fitness response in mountain populations of common lizards Lacerta vivipara. Glob Change Biol 12:392-402 
Chiba S (1998) A mathematical model for long-term patterns of evolution: effects of environmental stability and instability on macroevolutionary patterns and mass extinctions. Paleobiology 24:336-348

Coltman DW, O'Donoghue P, Jorgenson JT, Hogg JT and others (2003) Undesirable evolutionary consequences of trophy hunting. Nature 426:655-658

Du WG, Ji X, Zhang YP, Xu XF, Shine R (2005) Identifying sources of variation in reproductive and life-history traits among five populations of a Chinese lizard (Takydromus septentrionalis, Lacertidae). Biol J Linn Soc 85:443-453

$>$ Duncan RP, Forsyth DM (2006) Modelling population persistence on islands: mammal introductions in the New Zealand archipelago. Proc R Soc Lond B Biol Sci 273: 2969-2975

Epps CW, Palsboll PJ, Wehausen JD, Roderick GK, McCullough DR (2006) Elevation and connectivity define genetic refugia for mountain sheep as climate warms. Mol Ecol 15:4295-4302

Erwin DH (1998) The end and beginning: recoveries from mass extinctions. Trends Ecol Evol 13:344-349

Fernandez-Salvador R, Garcia-Perea R, Ventura J (2005) Effect of climatic fluctuations on body mass of a Mediterranean vole, Microtus cabrerae. Mamm Biol 70:73-83

Forcada J, Trathan PN, Reid K, Murphy EJ (2005) The effects of global climate variability in pup production of Antarctic fur seals. Ecology 86:2408-2417

Forchhammer MC, Clutton-Brock TH, Lindstrom J, Albon SD (2001) Climate and population density induce long-term cohort variation in a northern ungulate. J Anim Ecol 70:721-729

Forsyth DM, Duncan RP, Bomford M, Moore G (2004) Climatic suitability, life-history traits, introduction effort, and the establishment and spread of introduced mammals in Australia. Conserv Biol 18:557-569

Graham CH, Moritz C, Williams SE (2006) Habitat history improves prediction of biodiversity in rainforest fauna. Proc Natl Acad Sci USA 103:632-636

Guralnick R (2007) Differential effects of past climate warming on mountain and flatland species distributions: a multispecies North American mammal assessment. Glob Ecol Biogeogr 16:14-23

Herfindal I, Saether BE, Solberg EJ, Andersen R, Hogda KA (2006) Population characteristics predict responses in moose body mass to temporal variation in the environment. J Anim Ecol 75:1110-1118

> Hickling R, Roy DB, Hill JK, Fox R, Thomas CD (2006) The distributions of a wide range of taxonomic groups are expanding polewards. Glob Change Biol 12:450-455

Humphries MM, Umbanhowar J, McCann KS (2004) Bioenergetic prediction of climate change impacts on northern mammals. Integr Comp Biol 44:152-162

IPCC (Intergovernmental Panel on Climate Change) (2007) Climate Change 2007: the physical science basis. Contribution of working group I to the 4th assessment report of the IPCC. Cambridge University Press, Cambridge

Isaac JL (2005) Potential causes and life-history consequences of sexual size dimorphism in mammals. Mammal Rev 35:101-115

Isaac JL, Johnson CN (2003) Sexual dimorphism and synchrony of breeding: variation in polygyny potential among populations in the common brushtail possum, Trichosurus vulpecula. Behav Ecol 14:818-822

Isaac JL, Williams SE (2007) Climate change and extinctions. In: Levin S (ed) Encyclopaedia of biodiversity. Academic Press, San Diego, CA

Jachmann H, Berry PSM, Imae H (1995) Tusklessness in African elephants: a future trend. Afr J Ecol 33:230-235
Johnson CN, Isaac JL (in press) Body size and extinction risk in Australian mammals: back to the critical weight range. Austral Ecol

> King SJ, Arrigo-Nelson SJ, Pochron ST, Semprebon GM and others (2005) Dental senescence in a long-lived primate links infant survival to rainfall. Proc Natl Acad Sci USA 102:16579-16583

Kruuk LEB, Clutton-Brock TH, Rose KE, Guinness FE (1999) Early determinants of lifetime reproductive success differ between the sexes in red deer. Proc R Soc Lond B Biol Sci 266:1655-1661

Langvatn R, Mysterud A, Stenseth NC, Yoccoz NG (2004) Timing and synchrony of ovulation in red deer constrained by short northern summers. Am Nat 163:763-772

Lardies MA, Bozinovic F (2006) Geographic covariation between metabolic rate and life-history traits. Evol Ecol Res 8:455-470

Learmonth JA, MacLeod CD, Santos MB, Pierce GJ, Crick HQP, Robinson RA (2006) Potential effects of climate change on marine mammals. Oceanogr Mar Biol Annu Rev 44:431-464

MacLeod CD, Bergona Santos M, Reid RJ, Scott BE, Pierce GJ (2007) Linking sandeel consumption and the likelihood of starvation in harbour porpoises in the Scottish North Sea: could climate change mean more starving porpoises? Biol Lett 3:185-188

McArthur RH, Wilson EO (1967) The theory of island biogeography. Princeton University Press, Princeton

McDonald KA, Brown JH (1992) Using montane mammals to model extinctions due to global change. Conserv Biol 6:409-415

McKinney ML (1997) Extinction vulnerability and selectivity: combining ecological and paleontological views. Annu Rev Ecol Syst 28:495-516

McKinney ML, Lockwood JL (1999) Biotic homogenization: a few winner replacing many losers in the next mass extinction. Trends Ecol Evol 14:450-453

McMahon CR, Burton HR (2005) Climate change and seal survival: evidence for environmentally mediated changes in elephant seal, Mirounga lonina, pup survival. Proc R Soc Lond B Biol Sci 272:923-928

Millien V, Lyons SK, Olson L, Smith FA, Wilson AB, YomTov Y (2006) Ecotypic variation in the context of global climate change: revisiting the rules. Ecol Lett 9: 853-869

Mitchell CD, Maher CR (2006) Horn growth in male pronghorns Antilocapra americana: selection for precocial maturation in stochastic environments. Acta Theriol 51: 405-409

Møller AP, Szep T (2005) Rapid evolutionary change in a secondary sexual character linked to climatic change. J Evol Biol 18:481-495

Munoz AR, Real R (2006) Assessing the potential range expansion of the exotic monk parakeet in Spain. Divers Distrib 12:656-665

Nicholls N, Alexander L (2007) Has the climate become more variable or extreme? Progress 1992-2006. Prog Phys Geogr 31:77-87

Nyari A, Ryall C, Peterson AT (2006) Global invasive potential of the house crow Corvus splendens based on ecological niche modelling. J Avian Biol 37:306-311

Pickering C, Good R, Green K (2004) Potential effects of global warming on the biota of the Australian Alps. A report for the Australian Greenhouse Office, Canberra

Pribil S, Houlahan JE (2003) Life-history strategies associated with local population variability confer regional stability. Proc R Soc Lond B Biol Sci 270:1419-1423 
Prinzing A, Brandle M, Pfeifer R, Brandl R (2002) Does sexual selection influence population trends in European birds? Evol Ecol Res 4:49-60

Purvis A, Gittleman JL, Cowlishaw G, Mace GM (2000) Predicting extinction risk in declining species. Proc R Soc Lond B Biol Sci 267:1947-1952

Quin DG, Smith AP, Norton TW (1996) Eco-geographic variation in size and sexual dimorphism in sugar gliders and squirrel gliders (Marsupialia: Petauridae). Aust J Zool 44:19-45

Reale D, McAdam AG, Boutin S, Berteaux D (2003) Genetic and plastic responses of a northern mammal to climate change. Proc R Soc Lond B Biol Sci 270:591-596

Russell AF, Clutton-Brock TH, Brotherton PNM, Sharpe LL, and others (2002) Factors affecting pup growth and survival in co-operatively breeding meerkats Suricata suricatta. J Anim Ecol 71:700-709

Sandvic H, Coulson T, Saether BE (2008) A latitudinal gradient in climate effects on seabird demography: results from interspecific analyses. Glob Change Biol 14:703-713

Smith FA, Betancourt JL (2006) Predicting woodrat (Neotoma) responses to anthropogenic warming from studies of the palaeomidden record. J Biogeogr 33:2061-2076

Smith FA, Browning H, Shepherd UL (1998) The influence of climate change on the body mass of woodrats Neotoma in an arid region of New Mexico, USA. Ecography 21:140-148

Song Y, Chen D, Dong W (2006) Influence of climate on winter wheat productivity in different climate regions of China, 1961-2000. Clim Res 32:219-227

Storz JF, Balasingh J, Bhat HR, Nathan PT and others (2001) Clinal variation in body size and sexual dimorphism in an Indian fruit bat, Cynopterus sphinx (Chiroptera: Pteropodidae). Biol J Linn Soc 72:17-31

Thomas CD, Lennon JJ (1999) Birds extend their ranges northwards. Nature 399:213

Thomas CD, Cameron A, Green RE, Bakkenes M and others (2004) Extinction risk from climate change. Nature 427:145-148

Thomas CD, Franco AMA, Hill JK (2006) Range retractions and extinction in the face of climate warming. Trends Ecol Evol 21:415-416

Tuljapurkar S (1989) An uncertain life: demography in random environments. Theor Popul Biol 35:227-294

Editorial responsibility: Lee Hannah, Santa Barbara, California, USA
Tuljapurkar S (1990) Delayed reproduction and fitness in variable environments. Proc Natl Acad Sci USA 87:1139-1143

Twiss SD, Thomas C, Poland V, Graves JA, Pomeroy P (2007) The impact of climatic variation on the opportunity for sexual selection. Biol Lett 3:12-15

- Visser ME, Both C (2005) Shifts in phenology due to global climate change: the need for a yardstick. Proc R Soc Lond B Biol Sci 272:2561-2569

Walther GR, Post E, Convery P, Menzel A and others (2002) Ecological responses to recent climate change. Nature 416:389-395

Weatherhead PJ (2005a) Effects of climate variation on timing of nesting, reproductive success, and offspring sex ratios of red-winged blackbirds. Oecologia 144:168-175

Weatherhead PJ (2005b) Long-term decline in a red-winged blackbird population: ecological causes and sexual selection consequences. Proc R Soc Lond B Biol Sci 272: 2313-2317

Welbergen JA, Klose SM, Markus N, Eby P (2008) Climate change and the effects of temperature extremes on Australian flying-foxes. Proc R Soc Lond B Biol Sci 275: 419-425

Wilson RJ, Gutierrez D, Gutierrez J, Martinez D, Agudo R, Monserrat VJ (2005) Changes to the elevational limits and extent of species ranges associated with climate change. Ecol Lett 8:1138-1146

Yoccoz NG, Mesnager S (1998) Are alpine bank voles larger and more sexually dimorphic because adults survive better? Oikos 82:85-98

Yom-Tov Y (2001) Global warming and body mass decline in Israeli passerine birds. Proc R Soc Lond B Biol Sci 268: 947-952

Yom-Tov Y, Yom-Tov S (2004) Climatic change and body size in two species of Japanese rodents. Biol J Linn Soc 82:263-267

Yom-Tov Y, Yom-Tov J (2005) Global warming, Bergmann's rule and body size in the masked shrew Sorex cinereus Kerr in Alaska. J Anim Ecol 74:803-808

Yom-Tov Y, Heggberget TM, Wiig O, Yom-Tov S (2006a) Body size changes among otters, Lutra lutra, in Norway: the possible effects of food availability and global warming. Oecologia 150:155-160

Yom-Tov Y, Yom-Tov S, Wright J, Thorne CJR, Du Feu R (2006b) Recent changes in body weight and wing length among some British passerine birds. Oikos 112:91-101

Submitted: October 22, 2007; Accepted: March 17, 2008

Proofs received from author(s): May 8, 2008 